(C) 2017. This manuscript version is made available under the CC-BY-NC-ND 4.0 license http:// creativecommons.org/licenses/by-nc-nd/4.0/

Disentangling development of sensation seeking, risky peer affiliation, and binge drinking in adolescent sport.

Addictive Behaviors

March 2017

Catherine Frances Drane, Kathryn L. Modecki, \& Bonnie L. Barber

School of Applied Psychology, Menzies Health Institute Queensland, Griffith University;

Murdoch University

Portions of this research were supported through three grants under the Australian Research Council's Discovery Projects funding scheme: DP0774125 and DP1095791 to Bonnie Barber and Jacquelynne Eccles, and DP130104670 to Bonnie Barber, Kathryn Modecki, and Jacquelynne Eccles. The Australian Research Council had no role in the study design, collection, analysis or interpretation of the data, writing the manuscript, or the decision to submit the paper for publication.

We would like to thank the high school principals, their staff, and the students who participated in the YAPS-WA study. We are grateful to everyone in the YAPS-WA team, with special thanks to Corey Blomfield Neira, Bree Abbott, Lynette Vernon, and Stuart Watson for their contributions to data collection. 


\begin{abstract}
Purpose: To describe simultaneous within-person change in adolescent binge drinking, sensation seeking and risky peer affiliation for adolescents in sport across grades 8-10. Methods: Longitudinal data from 502 adolescent sport participants were analyzed. A multivariate growth curve model tracked early levels and concurrent change in binge drinking, sensation seeking, and risky peers in sports across three years.

Results: Findings revealed that early levels of sensation seeking and risky peers in sport were positively and significantly associated with early levels of binge drinking. Further, early high levels of sensation seeking predicted increases in risky peer associations and binge drinking.

Importantly, developmental increases in risky peer associations paralleled developmental increases in binge drinking, even after accounting for development of sensation seeking. Conclusions: It is important to identify factors that place adolescents at increased risk for escalations in binge drinking, especially within settings known to be problematic. Sensation seeking is a particularly potent driver of adolescent binge drinking within the extracurricular sport context. Further, accelerations in binge drinking travel hand-in-hand with affiliating with risky peers in sport.
\end{abstract}

Keywords: Binge drinking; Adolescence; Sensation seeking; Risky peers; Sport. 


\section{Disentangling Development of Sensation Seeking, Risky Peer Affiliation, and Binge \\ Drinking in Adolescent Sport.}

Binge drinking is pervasive among adolescents and is an important public health concern. Research suggests that approximately $14 \%$ of US adolescents have been drunk in the past month and 17\% of Australian adolescents binge drink on a monthly basis (Australian Institute of Health and Welfare, 2010; Johnston, O'Malley, Bachman, \& Schulenberg, 2012). Generally, binge drinking increases during adolescence and this increase is particularly troublesome given links between adolescent binge drinking and later alcohol-related problems (Kwan, Cairney, Faulkner, \& Pullenayegum, 2012). Further, continued alcohol abuse is associated with negative physical and mental health consequences, such as coronary heart disease, aggression, and mood disorders (Brook, Cohen, \& Brook, 1998). For this reason, identifying developmental factors that predict increases in binge drinking during adolescence is imperative.

Serious health consequences are associated with binge drinking during adolescence, and certain contexts are believed to increase this risk. In particular, participation in extracurricular sports has been shown to increase adolescents' likelihood of binge drinking (Lisha, \& Sussman, 2009; Mays et al., 2010). Illustratively, using latent growth curve analysis, Wichstrom \& Wichstrom (2009) demonstrated that initial levels of sport participation predicted growth in binge drinking over time. The link between sport participation and alcohol use is fairly robust (Barber, Eccles, \& Stone, 2001; Peck, Vida, \& Eccles, 2008). In a recent systematic review, more than $80 \%$ of published longitudinal studies reported a significant link between youth sport participation and higher alcohol use (Kwan et al., 2014). This mounting evidence makes clear that supervised, organised sport participation is associated with problematic drinking (Busseri et al., 2010; Eccles, \& Barber, 
1999). However, research has not adequately identified the processes that explain this growth in problematic drinking among youth sports participants.

There are complementary explanations related to the specific role of sensation seeking and heavy binge drinking in adolescent sport. One is that adolescents who are high in sensation seeking are drawn to sport and these adolescents are also prone to binge drinking. The other is that such risk-seeking participants are drawn together in sporting contexts, and it is the influence of spending time with other risky peers that leads adolescents to engage in and escalate binge drinking. There is evidence for both propositions.

First, there is empirical support for associations between sensation seeking - pursuit of varied, novel, and intense experiences—and alcohol involvement, particularly binge drinking (Wilkinson et al., 2011; Hittner, \& Swickert, 2005;). High sensation seekers are also more likely to initiate substance use, such as alcohol use, at an early age and become established users, relative to low (Bates, \& Pandina, 1991; Quinn, Stappenbeck, \& Fromme, 2011). In fact, sensation seeking is regarded as one of the major individual predictors of adolescent alcohol use and binge drinking (Donohew, et al., 1999; Quinn, Stappenbeck, \& Fromme, 2011). This desire to seek out novel and exciting experiences also characterizes adolescents who engage in organized sports (Goma-i-Freixanet, Martha \& Muro, 2012; Zuckerman, 2007). Adolescents who participate in sports are higher in sensation seeking than adolescents who do not (Zuckerman, 1994). Thus youth who participate in sports can generally be characterized as sensation seekers, and this high sensation seeking may explain why youth in sports tend to binge drink. Importantly, studies also suggest sensation seeking can be shaped, and as a result should be conceptualized as an individual difference that changes over time (Harden \& Tucker-Drob, 2011; Quinn \& Harden, 2013). Increases in 
sensation seeking during early adolescence are developmentally normative, followed by declines, but there is also considerable heterogeneity in rate and direction of change over time (Harden, \& Tucker-Drob, 2011).

Second, associating with risk-taking friends is a complementary explanation for known links between extracurricular sport participation and binge drinking. In general, spending time with risky peers is a risk factor for binge drinking during adolescence. As the number of peers who drink increases in one's network, the risk of binge drinking increases (Costa, Jessor, \& Turbin, 1999). For example, using latent growth mixture modelling, Martino and colleagues (2009) found close correspondence over time between heavy drinking and associations with peers who drink. This link between risky peers and binge drinking is important, because extracurricular sport contexts are characterised by a higher proportion of friends who drink than are many other contexts (Barber et al., 2005). As a result, it may be the case that increases in binge drinking among adolescent sport participants are an outgrowth of associations with risky peers, who are likewise drawn to the sport environment.

Involvement in sport exposes adolescents to peers who are themselves embedded within a pro-drinking culture (Mallam, 2006). Participating in sport influences both friend selection and ensconces youth in a culture in which they build shared values with risky peers. As adolescents are heavily influenced by peer norms, beliefs about how much their peers drink, referred to as descriptive drinking norms, represent a major social foundation for binge drinking (Fredricks \& Eccles, 2006) and alcohol use (Larimer et al., 2011). Adolescents tend to overestimate their peers' alcohol consumption (Borsari \& Carey, 2003), and this may be particularly true in sport, which has positive alcohol norms, including expectations that athletes should drink. These drinking expectations are based on perceptions 
of the groups' approval of drinking, known as injunctive norms, and studies show that individuals tend to perceive greater approval of drinking than is actually the case (DeMartini et al., 2011; LaBrie, Napper, \& Ghaidarov, 2012).

Collectively, the current study examines the role of these complementary explanations — sensation seeking and risky peers - that may help to explain accelerations in binge drinking among adolescent sport participants. Following adolescents who played sport across grades 8-10, we concurrently modelled early levels and developmental change in sensation seeking, association with risky peers in sports, and binge drinking. We examined whether within-person change in one construct (e.g. risky peers) travelled in tandem with change in another (e.g. binge drinking) controlling for developmental change in a theoretically important third variable (e.g. sensation seeking). Within these models, the predictive effects of early levels of each construct on growth in the others were specified. This approach reveals whether risk factors continue to increase in alignment with escalating binge drinking and whether early levels of risk predict subsequent binge drinking change.

\section{Methods}

\section{Participants}

Participants were from the Youth Activity Participation Study (YAPS), a longitudinal study of adolescent extracurricular activity involvement and development. Participants were from 34 public (45.9\%) and private (54.1\%) high schools across Western Australia. Because our study focused on sport participants, only adolescents who participated in sport across three consecutive years were included in analyses. Adolescents were identified as such using a validated measure (Barber, Stone, \& Eccles, 2005). At each wave adolescents were asked questions relating to their sport (e.g. risky peers). Longitudinal data were available for 502 adolescents who identified as sport participants (44\% male) in eighth grade $\left(M_{\text {age }}=12.99\right.$, 
$S D_{\text {age }}=.33$, Range $_{\text {age }}=12-14$ years) and continued for the next two years (approximately

$37 \%$ of the total sample).

\section{Procedure}

Ethical approval was obtained from the University Human Research Ethics

Committee. Study participation required active informed parent and student consent.

\section{Measures}

Scale reliabilities, descriptive statistics, and proportion of sample binge drinking at least once in the previous year, are presented in Table 1.

\section{Sensation seeking.}

Sensation seeking scale consisted of the mean of three items drawn from the NEO Personality Inventory (Costa, \& McCrae, 1992) and measured across three waves. I often crave excitement; I have sometimes done things just for "kicks" or "thrills"; I like to be where the action is. Items were measured on a 5-point scale, from 1 'strongly disagree' to 5 'strongly agree'. This scale showed validity and was positively associated with impulsivity $r$ $(490)=.522, \mathrm{p}<.001)$

\section{Binge drinking.}

Binge drinking was measured using one item adapted from the Michigan Study of Adolescent and Adult Life Transitions (MSALT), which captures variability in frequencies for both low and high levels of binge drinking. The item asks "In the past 6 months, how often have you had more than 5 alcoholic drinks on one occasion?" Responses were rated on an 8 -point scale, from $1=$ none to $8=31$ or more times. Previous research points to its validity (Kwan et al., 2012; Mays et al., 2010; Modecki, Barber, \& Eccles, 2014). The measure showed validity in our sample and was positively associated with illegal drug use $r$ $(490)=.442, p<.001)$. 


\section{Risky peers in sport.}

Risky peers in sport scale consisted of the mean of three items adapted from Fredricks and Eccles (2005) and measured across three waves. The peer items include: What proportion of your friends participating in this sport: Regularly drink alcohol? Regularly use illegal drugs? Likely to skip class? Items were measured on a 5- point scale; from 1 (none) to 5 (all). Previous research points to the measure's validity (Barber et al., 2005; Eccles et al., 2003) and as expected in our sample, it was negatively associated with prosocial peers $r(154)=-.338, p<.001$.

\section{Socio-economic status (SES).}

School level SES (Blomfield \& Barber, 2011) was obtained from the Index of Community Socio-Educational Advantage (ICSEA). The ICSEA is calculated for each school in the state using data from the Australian Bureau of Statistics, and draws on the education, occupation, income, ethnicity, and single parent status of each student's household (Australian Curriculum, Assessment and Reporting Authority 2015). Schools are assigned a relative score describing their comparative socio-educational advantage and schools ranged from $+/$ - two standard deviations from the state mean.

\section{Analytic approach}

In order to assess within-person change in each construct and whether factors change together over time, we estimated a series of latent growth curve models (LGM). Univariate growth curves, parallel process growth curves, and a multivariate growth curve model, were estimated in Mplus v. 7.1 (Muthén, \& Muthén, 1998-2012) using maximum likelihood estimation robust to non-normality. Data were analysed in four steps. First we fit unconditional univariate models of change for each of the three constructs in order to model early mean levels (intercept) and change (slope) in each variable over time, and associated 
variability. Second, we estimated a series of conditional models with study covariates. Third, we fit conditional parallel process growth curve models. These models allowed for correlated intercepts and correlated changes among all possible parallel construct pairs and slopes were also regressed on intercepts. Finally, as described in Figure 1, we modelled all three variables together within a multivariate growth curve. This model allowed us to test whether time 1 sensation seeking, risky peers in sport, and binge drinking predicted subsequent change in the other constructs, accounting for each construct's own subsequent change. With the exception of the unconditional models, all models accounted for effects of demographics by regressing latent intercept and change factors onto gender and SES. 
Figure 1 Schematic representation of the Multivariate Growth Curve for Sensation Seeking, Risky Peers, and Binge Drinking in adolescent sport.

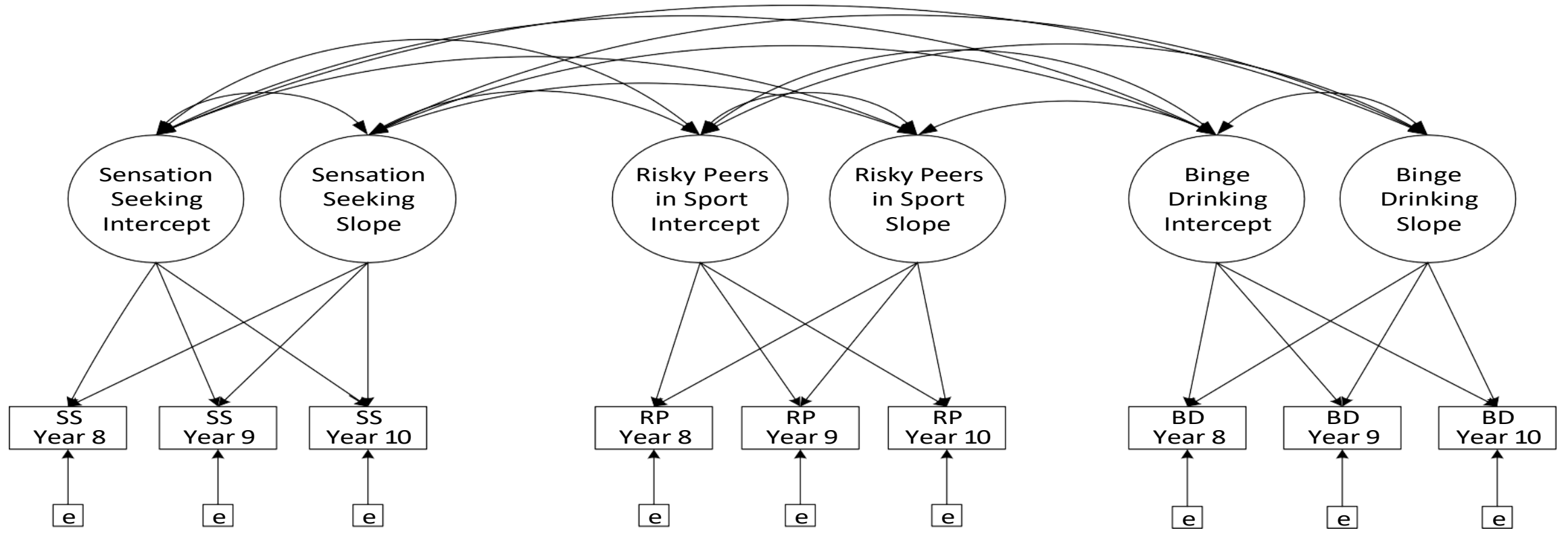

Note . SS = Sensation Seeking, $\mathrm{RP}=$ Risky Peers, $\mathrm{BD}=$ Binge Drinking, $\mathrm{e}=$ Error. Model includes the demographic variables gender and socioeconomic status as exogenous covariates. 
Table 1 Scale reliability and descriptive statistics for sensation seeking, risky peers in sport and binge drinking.

Scale Reliability and Descriptive Statistics

\begin{tabular}{|c|c|c|c|}
\hline & Time 1 & Time 2 & Time 3 \\
\hline \multicolumn{4}{|l|}{ Sensation Seeking } \\
\hline Cronbach Alpha & .70 & .81 & .79 \\
\hline Mean (Scaled Score) & 3.35 & 3.14 & 3.23 \\
\hline Standard Deviation & 1.52 & .96 & .92 \\
\hline \multicolumn{4}{|l|}{ Risky Peers } \\
\hline Cronbach Alpha & .66 & .78 & .77 \\
\hline Mean (Scaled Score) & 1.19 & 1.46 & 1.82 \\
\hline Standard Deviation & .37 & .69 & .83 \\
\hline \multicolumn{4}{|l|}{ Binge Drinking ( 1 item) } \\
\hline Mean & 1.09 & 1.38 & 1.83 \\
\hline Standard Deviation & .42 & .98 & 1.52 \\
\hline$\%$ Binge Drinking & $\underline{6 \%}$ & $17 \%$ & $\underline{31 \%}$ \\
\hline
\end{tabular}

\section{Results}

\section{Univariate Growth Curves}

To examine within-person changes in each construct, a series of LGMs were run.

Results and model fits for unconditional and conditional models are presented in Table 2. Model 1, presents the unconditional univariate models. As shown, mean initial levels of each construct were significantly different from zero. Early levels of sensation seeking were relatively high, however, early levels of risky peers and binge drinking were low, equivalent to approximately no risky peers and no binge drinking. There were also significant individual differences in initial levels of risky peers and sensation seeking. Further, there were significant linear increases in proportion of risky peers and binge drinking and significant linear declines in sensation seeking over time. Moreover, there were significant individual differences in degree of change over time for risky peers and binge drinking. Model 2, presents conditional univariate models. Boys and low SES youth 
had higher initial levels of risky peers. Low SES was associated with higher initial levels of binge drinking, but slower increases in binge drinking over time.

\section{Parallel Process Growth Curves}

Next, a series of parallel process models assessed associations between paired trajectories. Three parallel process models were estimated to evaluate correlations among early levels (intercepts) and growth (slopes) in each of the coupled trajectories. Slopes were regressed on intercepts to determine the effect of early levels of one construct on change in the other. Table 3 presents model fits for each parallel process model. Table 4 presents intercept-to-intercept and slope-to-slope standardized correlation coefficients, and unstandardized intercept-slope regression coefficients for the models. There were significant positive correlations among intercept and change factors for the binge drinking and risky peer model and the binge drinking and sensation seeking model. Significant positive correlations were found between risky peer and sensation seeking intercepts. In addition, higher initial levels of sensation seeking predicted steeper increases in binge drinking. Higher initial level of sensation seeking also predicted steeper increases in proportion of risky peers across time. Finally, higher initial levels of risky peers predicted steeper increases in binge drinking. 
Table 2 Univariate models and effects of covariates on risky peers, binge drinking and sensation seeking in adolescent sport.

\begin{tabular}{|c|c|c|c|c|c|c|}
\hline & \multicolumn{2}{|c|}{ Risky Peers } & \multicolumn{2}{|c|}{ Binge Drinking } & \multicolumn{2}{|c|}{ Sensation Seeking } \\
\hline & Model 1 & Model 2 & Model 1 & Model 2 & Model 1 & Model 2 \\
\hline \multicolumn{7}{|l|}{ Fixed effects } \\
\hline Intercept (Grade 8 mean) & $1.14(.02) * * *$ & $1.21(.05)^{* * *}$ & $1.09(.02)^{* * *}$ & $1.18(.06) * * *$ & $3.40(.06) * * *$ & $3.49(.15)^{* * *}$ \\
\hline Gender $(0=$ male $)$ & & $.02(.04)$ & & $.06(.04)$ & & $.06(.11)$ \\
\hline SES & & $-.00(.00)$ & & $-.01(.00)^{*}$ & & $-.00(.00)$ \\
\hline Linear slope (Time) & $.32(.02)^{* * *}$ & $.34(.05)^{* * *}$ & $.34(.03)^{* * *}$ & $.60(.08) * * *$ & $-.19(.07)^{* *}$ & $-.34(.28)$ \\
\hline Gender & & $.02(.04)$ & & $-.03(.06)$ & & $-.04(.15)$ \\
\hline SES & & $-.00(.00)$ & & $-.01(.00)^{* * *}$ & & $.00(.02)$ \\
\hline \multicolumn{7}{|l|}{ Random effects } \\
\hline Intercept & $.10(.04)^{* *}$ & $.10(.04)^{* *}$ & $.16(.08)$ & $.15(.08)$ & $.33(.05)^{* * *}$ & $.33(.05)^{* * *}$ \\
\hline Linear slope & $1(.02) * * *$ & $.10(.02)^{* * * *}$ & $.24(.06)^{* * * *}$ & $.23(.06)^{* * * *}$ & $.22(.16)$ & $.34(.61)$ \\
\hline CFI & .98 & .98 & .95 & .95 & .99 & .90 \\
\hline RMSEA & .06 & .04 & .07 & .05 & .03 & .12 \\
\hline SRMR & .02 & .02 & .02 & .02 & .03 & .03 \\
\hline
\end{tabular}

Note. All conditional models include the demographic variables, gender and socioeconomic status, as exogenous covariates, therefore, reported variances are residual variances. CFI = Comparative Fit Index; RMSEA = Root Mean Square of Approximation; SRMR = Standardized Root Mean Square Residual.

$*=p<.05, * *=p<.01, * * *=p<.001$ 
Table 3 Model fit for parallel process models.

Overall Model Fit for Parallel Process models

\begin{tabular}{llccc}
\hline Variables & \multicolumn{1}{c}{$\chi^{2}$} & CFI & RMSEA & SRMR \\
\hline Sensation Seeking \& Binge Drinking & $24.24^{*}$ & .97 & .04 & .04 \\
Risky Peers \& Binge Drinking & $37.68^{* *}$ & .93 & .06 & .04 \\
Sensation Seeking \& Risky Peers & $46.78^{* * *}$ & .93 & .07 & .04 \\
\hline
\end{tabular}

Note. All models include the demographic variables, gender and socioeconomic status, as covariates.

$*=p<.05, * *=p<.01, * * *=p<.001$.

Table 4 Factor Correlations and Regression Coefficients from the Parallel Process Models.

\begin{tabular}{|c|c|c|c|c|c|c|}
\hline \multirow[b]{2}{*}{ Factors } & \multicolumn{2}{|c|}{ Sensation Seeking } & \multicolumn{2}{|c|}{ Risky Peers } & \multicolumn{2}{|c|}{ Binge Drinking } \\
\hline & Intercept & Slope & Intercept & Slope & Intercept & Slope \\
\hline
\end{tabular}

Risky Peers

$\begin{array}{rlr}\text { Intercept } & .43 * * * & -.06 \\ \text { Slope } & .14 * * & .36\end{array}$

Binge Drinking

$\begin{array}{rllll}\text { Intercept } & .16^{*} & .03 & .29 * * * & .01 \\ \text { Slope } & .39 * * * & .21 & .50 * * & .78 * * *\end{array}$

Note. All models include the demographic variables, gender and socioeconomic status, as covariates. Values are standardized correlation coefficients for correlated intercepts and changes, and unstandardized intercept-slope regression coefficients. $*=p<.05, * *=p<.01, * * *=p<.001$.

\section{Multivariate Growth Curve}

Finally, a multivariate growth curve model was estimated to test whether early sensation seeking, association with risky peers in sport, and binge drinking predicted subsequent change in the other constructs, accounting for each construct's own change. All slopes were correlated as were all intercepts, permitting a test of all correlated changes. Further, all slopes were regressed onto all intercepts, testing whether early levels of one construct predicted subsequent change in another, controlling for change in an important third variable. Table 5 presents intercept-to- 
intercept and slope-to-slope correlation coefficients, intercept-slope regression coefficients, as well as model fit. $\mathrm{R}^{2}$ for the latent variables shows that the intercepts for sensation seeking, risky peers, and binge drinking accounted for $6.5 \%, 6.5 \%$ and $2.5 \%$ respectively, of the proportion of the shared variance, indicating small effects. The proportion of shared variance for the slopes of sensation seeking, risky peers, and binge drinking accounted for $6.5 \%, 11.3 \%$ and $31.1 \%$ respectively, indicating small effects for sensation seeking and risky peers, and a large effect for binge drinking.

There were significant correlations among intercept and change factors (see Table 5). Initial levels of the three constructs were positively associated, indicating that higher levels of one construct were associated with higher levels of the other two. Thus, higher early levels of sensation seeking were associated with a greater proportion of risky peers in sport and higher binge drinking. Further, slopes were positively correlated for binge drinking and risky peers, indicating that as binge drinking increased over time, youth spent time with a greater proportion of risky peers, controlling for simultaneous change in sensation seeking. Moreover, higher initial levels of sensation seeking predicted steeper increases in binge drinking over time and predicted greater increases in the proportion of risky peers in sport. 
Table 5 Factor Correlations and Regression Coefficients from the Multivariate Growth Curve Model for Sensation Seeking, Risky Peers, and Binge Drinking.

\begin{tabular}{|c|c|c|c|c|}
\hline \multirow[b]{2}{*}{ Factor } & \multicolumn{2}{|c|}{ Sensation Seeking } & \multicolumn{2}{|c|}{ Risky Peers } \\
\hline & Intercept & Slope & Intercept & Slope \\
\hline \multicolumn{5}{|l|}{ Sensation Seeking } \\
\hline \multicolumn{5}{|l|}{ Intercept } \\
\hline \multicolumn{5}{|l|}{ Slope } \\
\hline \multicolumn{5}{|l|}{ Risky Peers } \\
\hline Intercept & $.42 * * *$ & -.04 & & \\
\hline Slope & $.15^{* *}$ & .34 & & \\
\hline \multicolumn{5}{|l|}{ Binge Drinking } \\
\hline Intercept & $.17 *$ & -.01 & $.33 * *$ & .03 \\
\hline Slope & $.33 * * *$ & .25 & .27 & $.77 * * *$ \\
\hline Model Fit & $\chi^{2}$ & CFI & RMSEA & SRMR \\
\hline
\end{tabular}

Note. Model includes the demographic variables, gender and socioeconomic standing, as covariates. Values are standardized correlation coefficients for correlated intercepts and changes, and unstandardized Intercept-slope regression coefficients. $\mathrm{SS}=$ Sensation Seeking, $\mathrm{RP}=$ Risky Peers, $\mathrm{BD}=$ Binge Drinking. $*=p<.05, * *=p<.01, * * *=p<.001$.

\section{Discussion}

One well-established risk factor for adolescent binge drinking is extracurricular sport participation. However, previous research has not disentangled whether, within sporting contexts, high rates of binge drinking are due to personality, due to associations with risky peers, or due to both. Establishing a temporal order of increased drinking, sensation seeking and risky peer exposure is especially difficult, as reciprocal relations are likely. By examining simultaneous change in all three indicators among adolescents participating in sport, this study offers important insight into the dynamic circumstances under which this context can promote dangerous drinking.

Our multivariate results show that adolescent athletes with early high levels of sensation seeking demonstrated more rapid increases in binge drinking across three years, controlling for subsequent changes in sensation seeking and in association with risky peers in sport. Further, 
youth with higher initial sensation seeking reported more rapid increases in their risky peer associations, albeit with a small effect size, again controlling for sensation seeking change and binge drinking change. These results make clear that early sensation seeking among youth sport participants can promote the acceleration of risk across the early high school years. That being said, the multivariate model also showed that escalations in binge drinking occurred in tandem with escalations in risky peer associations. Thus, among youth sport participants, accelerations in binge drinking go hand-in-hand with affiliation with risky sporting peers. Importantly, our model showed a large effect size for binge drinking. Of course, there was still remaining variance to be explained. Further models should thus include other putative drivers of adolescent binge drinking, including peer norms, both injunctive and subjective, and peer sensation seeking. In all, these results suggest that prevention programs to mitigate binge drinking among sport participants should be tailored to high sensation seeking youth (Donohew et al., 2000). Further, in that upsurges among the two are connected, addressing problematic peer norms in sporting contexts is arguably another useful target to limit accelerations in problematic drinking.

We also presented two notable findings from our univariate and parallel process models. First, within the univariate models, although binge drinking and association with risky peers increased over the course of three years, sensation seeking decreased. Previous research investigating sensation seeking over the course of adolescence has generally reported increases, or else a curvilinear pattern of change (Harden \& Tucker-Drob, 2011; Steinberg et al., 2008). The most likely explanation for our finding of decline is that as sport participants, youth were relatively high sensation seekers to begin with (Roberti, 2004; Zuckerman, 1994). Second, within the paired developmental trajectories, when sensation seeking was not taken into account, early risky peers in sport were associated with escalations in binge drinking over time. This finding 
dropped away in our multivariate model and highlights the importance of assessing binge drinking trajectories together, with both risky peer associations and sensation seeking. To provide an accurate account of early predictors and correlates of growth in adolescent binge drinking, scholars need to address the interplay between personality and risky peer affiliation, with problem drinking.

\section{Implications}

This study is the first to examine simultaneous relations between growth in binge drinking, sensation seeking, and risky peers within the context of adolescent sport participation. As a result, our findings have implications for prevention of adolescent binge drinking more generally, in addition to informing alcohol prevention efforts within the context of extracurricular sports. Study results substantiate the influence of early sensation seeking on binge drinking (Quinn, Stappenbeck, \& Fromme, 2011). Notably within a context that is known for dangerous drinking, our results demonstrate a robust association between this personality facet and increased risk for problems. Early high levels of sensation seeking were associated with increasingly problematic peer associations and also escalations in binge drinking across the early high school years. These results also highlight powerful ties between the development of adolescent binge drinking and risky peers in sport. Even after controlling for demographics and changes in sensation seeking, we found substantial support for correlated change in risky peer associations and binge drinking.

Why do risky peers in sport have such pernicious links to binge drinking? One explanation is that we began following adolescents soon after their transition to high school. This is a key period for forming and cultivating peer groups (Wigfield, Byrnes, \& Eccles, 2006). During this transition, sport participation may be an important pathway to establishing a peer 
network, providing a ready-made peer group which connects adolescent athletes with sporting peers, leading to opportunities to both play sport and socialise, further enhancing the potential for peer influence. Some of these sport peers may be characterized by high sensation seeking (Roberti, 2004) and also a propensity to drink alcohol (Modecki et al., 2014). Once integrated into a risky peer group, adolescents may further socialise with each other around heavy drinking (Centifanti et al., 2014) so that peer risk and binge drinking remain coupled.

Although study findings offer important insight into adolescent binge drinking they must be considered in light of several limitations. Our sample of Australian adolescent athletes may not be comparable to those in other industrialized countries. Moreover, it is possible that risky peers and sensation seekers choose to congregate in particular types of sports such as those with high levels of physical contact, and therefore risks may not be uniform across sports.

Additionally, we used a single item measure of binge drinking. Although there is good evidence of its validity (Kwan et al., 2012; Mays et al., 2010; Modecki, et al, 2014), future research could improve upon its use by further including a definition of 'drink' and consider using a continuous indicator of number of recent drinking episodes.

It is important to identify factors that place adolescents at increased risk for escalations in binge drinking, especially within settings that are known for problems. Our results indicate that sensation seeking may be a particularly potent driver of adolescent binge drinking within the context of extracurricular sport. A key finding from this study is that early sensation seeking drives increases in binge drinking among adolescent sport participants. Even accounting for the effects of sensation seeking, association with risky peers changed in tandem with adolescents' own drinking. Programs that target excitement-based motivations to drink (Conrod et al., 2011) 
and bolster positive, prosocial peer norms may be especially useful for guarding against escalations in binge drinking among youth sport participants. 


\section{References}

Australian Curriculum, Assessment and Reporting Authority (ACARA). (2015). What does the ICSEA value mean? www.acara.edu.au/vervel_resources/About_icsea_2014.pdf (Accessed July 15, 2015).

Australian Institute of Health and Welfare. 2010 National Drug Strategy Household Survey report. Drug Statistics Series No. 25. Cat. No. PHE 145. Canberra, Australia: AIHW; 2011.

Barber, B.L., Eccles, J.S., \& Stone, M.R. (2001). Whatever happened to the jocks, the brain, and the princess? Young adult pathways linked to adolescent activity involvement and social identity. Journal of Adolescent Research, 16, 429-455.

doi $10.1177 / 0743558401165002$.

Barber, B.L., Stone, M.R., \& Eccles, J.S. (2005). Adolescent participation in organized activities. In: Moore K, Lippman LH, eds. Conceptualizing and measuring indicators of positive development: What do children need to flourish? (pp. 133-146). New York: Springer.

Barber, B.L., Stone, M.R., Hunt, J.E., \& Eccles, J.S. (2005). Benefits of activity participation: The roles of identity affirmation and peer norm sharing. In: Mahoney JL, Larson RW, Eccles JS, eds. Organized activities as contexts of development: Extracurricular activities, after-school and community programs (pp. 185-210). Mahwah, NJ: Lawrence Erlbaum.

Bates, M.E., \& Pandina, R.J. (1991). Personality stability and adolescent substance use behavior. Alcoholism: Clinical and Experimental Research, 15, 471-477. doi 10.1111/j.1530-0277. 1991.tb00545.x

Blomfield, C.J., \& Barber, B.L (2011). Developmental experiences during extracurricular activities and Australian adolescents' self-concept: Particularly important for youth from 
disadvantaged schools. Journal of Youth \& Adolescence, 40,582-594.

doi.org/10.1007/s10964-010-9563-0.

Borsari, B., \& Carey, K. B. (2003). Descriptive and injunctive norms in college drinking: A meta-analytic integration. Journal of Studies on Alcohol, 64(3), 331-341. doi:10.15288/jsa.2003.64.331

Brook, J.S., Cohen, P., \& Brook, D.W. (1998). Longitudinal study of co-occurring psychiatric disorders and substance use. Journal of the American Academy of Child Adolescent Psychiatry, 37, 322-330. doi 10.1097/00004583-199803000-00018.

Busseri, M.A., Rose-Krasnor, L., Mark Pancer S., Pratt, M.W., Adams, G.R., Birnie-Lefcovich, S., Polivy, J., \& Gallander Wintre, M. (2010). A longitudinal study of breadth and intensity of activity involvement and the transition to university. Journal of Research on Adolescence, 21, 512-8. doi 10.1111/j.1532-7795.2010.00691.x.

Centifanti, M.L., Modecki, K.L., Wolf S., \& Gowling, H. (2014). Driving under the influence of peers: Does riskiness of the peer group matter? Journal of Research on Adolescence (in press).

Conrod, P.J., Castellanos-Ryan, N., \& Mackie, C. (2011). Long-term effects of a personalitytargeted intervention to reduce alcohol use in adolescents. Journal of Consulting and Clinical Psychology, 79, 296-306. doi 10.1037/a0022997.

Costa, M., Jessor, R., \& Turbin, M.S. (1999). Transition into adolescent problem drinking: the role of psychosocial risk and protective factors. Journal of Studies on Alcohol and Drugs, 60, 480-490. doi 10.15288/jsa.1999.60.480. 
Costa, P.T., \& McCrae, R.R. (1992). Revised NEO Personality Inventory (NEO-PI-R) and NEO Five-Factor Inventory (NEO-FFI) manual. Odessa, FL: Psychological Assessment Resources.

DeMartini, K. S., Palmer, R. S., Leeman, R. F., Corbin, W. R., Toll, B. A., Fucito, L. M., \& O'Malley, S. S. (2013). Drinking less and drinking smarter: Direct and indirect protective strategies in young adults. Psychology of Addictive Behaviors, 27(3), 615-626. doi:10.1037/a0030475.

Donohew, R.L., Hoyle, R.H., Clayton R.R., Skinner, W.F., Colon, S.E., \& Rice, R.E. (1999). Sensation seeking and drug use by adolescents and their friends: models for marijuana and alcohol. Journal of Studies on Alcohol and Drugs, 60, 622-631. doi 10.15288/jsa.1999.60.622.

Donohew, L., Zimmerman, R., Cupp, P. S., Novak, S., Colon, S., \& Abell, R. (2000). Sensation seeking, impulsive decision-making, and risky sex: Implications for risk-taking and design of interventions. Personality and Individual Differences, 28(6), 1079-1091. doi.org/10.1016/s0191-8869 (99) 00158-0.

Eccles, J.S., \& Barber, B.L. (1999). Student council, volunteering, basketball, or marching band: What kind of extracurricular involvement matters? Journal of Adolescent Research, 14, 1043. doi 10.1177/0743558499141003.

Eccles, J.S., Barber, B. L., Stone, M., \& Hunt, J. (2003). Extracurricular activities and adolescent development. Journal of Social Issues, 59(4), 865-889.

Fredericks, J.A., \& Eccles, J.S. (2006). Is extracurricular participation associated with beneficial outcomes? Concurrent and longitudinal relations. Developmental Psychology, 42, 698-713. doi 10.1037/0012-1649.42.4.698. 
Gomà-i-Freixanet1, M., Martha, C., \& Muro, A. (2012). Does the Sensation-Seeking trait differ among participants engaged in sports with different levels of physical risk? Anales de psicologia, 28, 223-232.

Harden, K.P., \& Tucker-Drob, E.M. (2011). Individual differences in the development of sensation seeking and impulsivity during adolescence: Further evidence for a dual systems model. Developmental Psychology, 47, 739-746. doi 10.1037/a0023279.

Johnston, L. D., O'Malley, P. M., Bachman, J. G., \& Schulenberg, J. E. (2012). The rise in teen marijuana use stalls, synthetic marijuana use levels, and use of "bath salts" is very low. Ann Arbor, MI: University of Michigan News Service. http://www.monitoringthefuture.org/data/12data.html\#2012data-drugs. [Accessed 05/03/15].

Kwan, M., Bobko, S., Faulkner, G., Donnelly, P., \& Cairney, J. (2014). Sport participation and alcohol and illicit drug use in adolescents and young adults: A systematic review of longitudinal studies. Addictive Behaviors, 39(3), 497-506.

doi:10.1016/j.addbeh.2013.11.006

Kwan, M.Y., Cairney, J., Faulkner, G.E., \& Pullenayegum, E.E. (2012). Physical activity and other health-risk behaviours during the transition into early adulthood: A longitudinal cohort study. American Journal of Preventive Medicine, 42, 14-20. doi.org/10.1016/j.amepre.2011.08.026.

LaBrie, J. W., Napper, L. E., \& Ghaidarov, T. M. (2012). Predicting driving after drinking over time among college students: The emerging role of injunctive normative perceptions. Journal of Studies on Alcohol and Drugs, 73 (5), 726. 
Larimer, M. E., Turner, A.P., Mallett, K.A., \& Geisner, I.M. (2004). Predicting drinking behavior and alcohol-related problems among fraternity and sorority members: Examining the role of descriptive and injunctive norms. Psychology of Addictive Behaviors, 18, 203212. doi 10.1037/0893-164x.18.3.203.

Larimer, M. E., Neighbors, C., LaBrie, J. W., Atkins, D. C., Lewis, M. A., Lee, C. M., Kilmer, J. R., Kaysen, D. L., Pedersen, E. R., Montoya, H., Hodge, K., Desai, S, Hummer, J. F., \& Walter, T. (2011). Descriptive drinking norms: For whom does reference group matter? $J$ Stud Alcohol Drugs, 72 (5), 833-43.

Lisha, N.E., Sussman, S. (2009). Relationship of high school and college sports participation with alcohol, tobacco, and illicit drug use: a review. Addictive Behaviors, 35, 399-407. doi 10.1016/j.addbeh.2009.12.032.

Mallam, M. (2006). A commentary on two of Australia's greatest consuming passions, alcohol and sport, and the regulation of the relationship between them. Australian and New Zealand Sports Law Journal, 1(1), 42-79.

Martino, S.C., Ellickson, P.L., \& McCaffery, D.F. (2009). Multiple trajectories of peer and parental influence and their associations with the development of adolescent heavy drinking. Addictive Behaviors, 34, 693-700. doi 10.1016/j.addbeh.2009.04.006.

Mays, D., DePadilla, K., Thompson N.J, Kushner, H.I., \& Windle, M. (2010). Sport participation and problem alcohol use: A multi-wave national sample of adolescents. American Journal of Preventive Medicine, 38, 491-498. doi.org/10.1016/j.amepre.2010.01.023.

Modecki, K. L., Barber, B. L., \& Eccles, J. S. (2014). Binge drinking trajectories across adolescence: For early maturing youth, extra-curricular activities are protective. Journal of Adolescent Health, 54(1), 61-66. 
doi: 10.1016/j.jadohealth.2013.07.032.

Muthén, L.K., \& Muthén, B.O. (1998 - 2012) Mplus User's Guide. $7^{\text {th }}$ ed. Los Angeles, CA: Muthén \& Muthén.

Peck, S.C., Vida, M., \& Eccles, J.S. (2008). Adolescent pathways to adulthood drinking: Sport activity involvement is not necessarily risky or protective. Addiction, 103, 69-83. doi 10.1111/j.1360-0443.2008.02177.x.

Quinn, P. D., \& Harden, K. P. (2013). Differential changes in impulsivity and sensation seeking and the escalation of substance use from adolescence to early adulthood. Development and Psychopathology, 25(1), 223-239. doi:10.1017/S0954579412000284

Quinn, P.D., Stappenbeck, C.A., \& Fromme, K. (2011). Collegiate heavy drinking prospectively predicts change in sensation seeking and impulsivity. Journal of Abnormal Psychology, 120, 543-556. doi: 10.1037/a. 0023159.

Roberti, J. (2004). A review of behavioral and biological correlates of sensation seeking. Journal of Research in Personality, 38, 256-279. doi: 10.1016/S0092-6566(03)00067-9.

Steinberg, L., Albert, D., Cauffman, E., Banich, M., Graham, S., \& Woolard, J. (2008). Age differences in sensation seeking and impulsivity as indexed by behavior and self-report: Evidence for a dual systems model. Developmental Psychology, 44, 1764-1778. doi: $10.1037 / \mathrm{a} 0012955$.

Wichstrom, T., Wichstrom, L. (2009). Does sports participation during adolescence prevent later alcohol, tobacco and cannabis use? Addiction, 104,138-149. doi: 10.1111/j.1360-0443.

Wigfield, A., Byrnes, J.P., \& Eccles J.S. (2006). Development during early and middle adolescence. In Alexander PA, Winne PH, eds. The handbook of educational psychology (pp. 87-113) Mahwah, NJ: Lawrence Erlbaum Associates. 
Wilkinson, A.V., Shete, S., Spitz, M.R, Swann, A.C. (2011). Sensation seeking, risk behaviors, and alcohol consumption among Mexican origin youth. Journal of Adolescent Health, 48, 65-72. doi 10.1016/j.jadohealth.2010.05.002

Zuckerman, M. (1994). Behavioral expressions and biosocial bases of sensation seeking. New York: Cambridge University Press.

Zuckerman, M., \& American Psychological Association. (2007). Sensation seeking and risky behavior. Washington, DC: American Psychological Association. doi:10.1037/11555-000 